\title{
Assessment of the Status of Contralateral Ear in Post-Operative Subjects of Unilateral Chronic Otorrhoea
}

\author{
Bhandari S ${ }^{1}$, Shrestha $S^{1}$, Paudel DR ${ }^{1}$
}

\begin{abstract}
Introduction: Chronic otitis media is one of the most common ear diseases in developing countries like Nepal and is important cause of the hearing loss. Chronic otitis media is rarely an isolated entity, because the responsible factors for its development in one ear in similar way will impact the contralateral ear, since both ears have a common "nasopharyngeal" drainage. Contralateral ear is defined as asymptomatic ear in cases of unilateral chronic otitis media. Aim: To evaluate the audiological profile of Contralateral ear in post-operative subjects of unilateral otorrhoea. Methods: Patients fulfilling criteria underwent Otoscopic examination, tuning fork test and pure tone audiometry. The findings of contralateral ear like retraction, tympanosclerotic patch (TS patch), thin, dull and atrophied tympanic membrane were noted. The final diagnosis with the type of surgery of diseased ear, as well as status of contralateral ear were entered into the proforma. All the patients were followed till three months in relation to anatomy of Tympanic membrane onotomicroscopy and pure tone audiometry respectively. Results: In postoperative cases of mucosal disease, the cases with abnormality in the contralateral ear reduced from 17 to 10 patients (30.3\%) and the normal patients increased from 16 to 23 cases (69.7\%). Likewise, in postoperative squamous disease, the cases with abnormality in the contralateral ear reduced from 14 to 11 patients (64.7\%) and the normal patients increased from 3 to 6 cases (35.3\%). Out of 50 cases, 14 cases (28\%) had defective hearing while 36 cases (72\%) had normal hearing in the contralateral ear respectively. Conclusions: The high incidence of occurrence of abnormality in contralateral ear indicate that both ears should be regarded as a pair. Unilateral Chronic otitis media should not be taken as a static phenomenon but as a continuous process in the other ear too.
\end{abstract}

\section{Keywords: Chronic otitis media, Contralateral ear, Tympanic membrane}

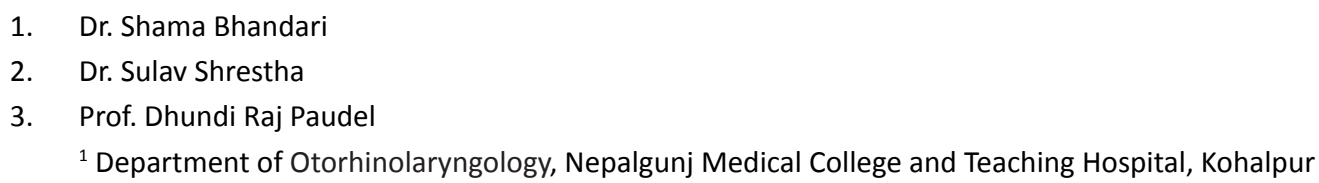

\section{Address for Correspondence:}

\author{
Dr. Shama Bhandari \\ Department of Otorhinolaryngology \\ Nepalgunj Medical College and Teaching Hospital \\ Kohalpur, Banke, Nepal \\ E-mail: dr.shama.bhandari@gmail.com
}

\section{INTRODUCTION}

Otorrhoea, exiting of any discharge from the ear is the foremost symptoms of ear disease The discharge may be from external, middle ear and the skull base as well but chronic middle ear cleft infection and inflammation are the most common cause for chronic otorrhoea requiring various modalities of surgical management Chronic otitis media(COM) is defined as chronic inflammation of the middle ear (ME) and/or mastoid associated with permanent perforation or retraction of the tympanic membrane (TM) with or without otorrhoea. ${ }^{1}$

There are two types of COM - one could be associated with transient or permanent otorrhoea with central perforation of tympanic membrane and the other with or without discharge with marginal perforations, retraction with the potentiality of or frank cholesteaoma. The former is classified as mucosal and the later as squamous type. ${ }^{2}$ COM, most likely is the result of earlier acute otitis media (AOM), negative ME pressure or otitis media with effusion (OME). Hearing loss associated with it is due to perforation of the ear drum and/or disruption of the ossicles. ${ }^{3} \mathrm{COM}$ is mostly associated with malfunction of Eustachian tube (ET). It is probable that a patient with unilateral discharge attributed to COM, may also have a disorder in the contralateral ear (CLE). ${ }^{4}$ CLE is defined as the asymptomatic ear or in cases with bilateral symptoms, the ear with clearly less symptoms based on hearing loss, otorrhoea and overall discomfort. ${ }^{2}$ It has become universal knowledge that COM is rarely an isolated disease. The factors responsible for initiating COM in one ear may as well affect the CLE since both ear share a common portal of aeration and drainage i.e. the nasopharynx. According to the continuum theory, unresolved OME later evolves into COM. Assessment of the clinico-pathological feature may reveal that states of CLE may indicate the etiology and evolution of disease of the worst 
ear. The affected ear may well be the suggestive of impending pathological end point of the CLE. ${ }^{5-8}$ The study of the CLE may provide clues to the pathophysiology of the primary disease of ear with full-blown disease, status of tubal function and contribute to the therapeutic planning. ${ }^{9}$

Though patients may attend ENT department with complains of ipsilateral ear discharge and without any complains of the contralateral ear its mandatory to examine both ear to rule out pathology in the asymptomatic ear. Sometimes non discharging ear may have more severe diseases.

\section{METHODS}

This study is Hospital based prospective, observational study done at Nepalgunj Medical College and Teaching hospital, Kohalpur from $1^{\text {st }}$ August, 2017 to $31^{\text {st }}$ July, 2018. Sample size was 50 using the formula for sample size.

Including criteria: unilateral otorrhoea for more than 10 years undergoing surgical operation with contralateral non discharging ear were included cases.

Excluding criteria: Patient with bilateral otorrhoea with perforation, previous history of surgery in CLE, CLE dead or not suitable for hearing aid and having acute active upper respiratory tract infection were excluded.

All patients were fully informed about the procedure and informed consent was taken. Detailed history along with nasal obstruction, discharge, allergy and sore throat were also emphasized. A proforma was designed and tested.

Examination of ear, nose and throat, Otoscopic examination, Tuning fork test, Audiometric examinations were done. CLE was examined for any abnormalities or pathologies of both parts of TM in terms of thinness, dullness and atrophy tympanosclerotic patch (TS patch), and pathologies like Perforation, retraction cholesteatoma and other rare pathologies too.

The degree of $\mathrm{HL}$ for $\mathrm{AC}$ thresholds and $\mathrm{BC}$ threshold were measured and calculated by taking average threshold of speech frequencies i.e. mean of hearing threshold at 0.5 , 1, 2, 4 Kilohertz $(\mathrm{KHz})$. Masked PTA was done if there was a difference of more than $40 \mathrm{~dB}$ between $\mathrm{AC}$ threshold of the test ear and the $B C$ threshold of the opposite ear or when the A-B gap of the poorer ear under test was more than $10 \mathrm{~dB}$. The final diagnosis with the type of surgery of diseased ear, as well as CLE were entered into the proforma. All the patients were followed up at three months in relation to anatomy of TM (otomicroscopy) and pure tone audiometry (PTA)

The data collected was entered into SPSS software version 20 and further analysis was performed. The data was tabulated and the result of study were analyzed using statistical package for social science (SPSS) 20.0 and Microsoft word and Microsoft excel were used to generate graphs, tables etc. Before starting the study, ethical approval was taken from institutional review committee (IRC) of NGMC. Every participant's willingness was considered before including them in the study.

\section{RESULTS}

The most common age group affected by the disease was 1020 and 21-30 years and the least commonly affected age group was $40-50$ years. There were 29 (58\%) female and $21(42 \%)$ male patient. Out of 50 cases of COM, 33(66\%) patients had mucosal diseases and 17 (34\%) had squamous disease suggesting a higher preponderance of mucosal disease.

\begin{tabular}{ccccccc}
\multicolumn{3}{c}{ Size and site of perforation (\%) } & \multicolumn{2}{c}{ Retraction } \\
Small pars & $\begin{array}{c}\text { Medium } \\
\text { tensa } \\
\text { pars tensa }\end{array}$ & Subtotal & $\begin{array}{c}\text { Attic } \\
\text { perforation }\end{array}$ & $\begin{array}{c}\text { PSRP } \\
(0-40 \%)\end{array}$ & $\begin{array}{c}\text { PT } \\
\text { retraction }\end{array}$ & Sclerosis \\
16 & 12 & 4 & 3 & 8 & 4 & 3 \\
$(32 \%)$ & $(24 \%)$ & $(8 \%)$ & $(6 \%)$ & $(16 \%)$ & $(8 \%)$ & $(6 \%)$
\end{tabular}

Table I: Pre-operative Otoscopic abnormality of TM of ipsilateral ear

Preoperative otoscope of ipsilateral ear showed 16(32\%) small pars tensa, $12(24 \%)$ medium pars tensa, $3(6 \%)$ attic perforation. (Table I)

Preoperative assessment of CLE ear revealed pathology exclusively in PT. Before undertaking operation, the assessment of the status of CLE in the mucosal COM cases revealed that $17(51.6 \%)$ patients had various pathological findings in the CLE while other $16(48.4 \%)$ cases were observed to have normal otological and audiological status. Preoperative assessment in squamous COM cases (17) showed that $14(82.3 \%)$ had pathological features on CLE's as well, and only $3(17.7 \%)$ of them were having normal otological and audiological status.

Out of 50 cases, the total number of patients with abnormalities of TM in the CLE were 31 (62\%). In patients with mucosal COM, retracted PT was seen in 6 (21.2\%), tympnosclerotic patch in $4(12.1 \%)$, opaque TM was observed in $2(6 \%)$, thinned out TM was noted in $3(9 \%)$ cases. In addition, both retracted TM and TS patch was seen in $1(3 \%)$ while none of the patients having mucosal type of COM had retracted PF. Retraction and sclerosis of PT were seen twice more often in mucosal type of disease. Furthermore, asymptomatic PF retraction was noticed in $4(17.6 \%)$ of squamous type of COM in CLE. Sclerosis of TM was seen in equal number of cases in both type of COM, yet being numerically lesser in number than mucosal type. The thicker and opaque PT was $2(6.1 \%)$ in mucosal type and 3 $(17.6 \%)$ in squamous type which is an important feature of squamous type. Tympanic membrane retraction associated with TS patch 4 (23.5\%)was a dominant feature of squamous type of COM. Thinning of TM, perhaps a sign of spontaneous healed perforation was observed exclusively in mucosal type of disease. (Table II) 


\begin{tabular}{|ccccccccc|}
$\begin{array}{c}\text { Type of } \\
\text { COM }\end{array}$ & $\begin{array}{c}\text { Retracted } \\
\text { PT }\end{array}$ & $\begin{array}{c}\text { Retracted } \\
\text { PF }\end{array}$ & $\begin{array}{c}\text { T.S } \\
\text { patch }\end{array}$ & $\begin{array}{c}\text { Opaque } \\
\text { TM }\end{array}$ & $\begin{array}{c}\text { Thin } \\
\text { TM }\end{array}$ & $\begin{array}{c}\text { Retracted } \\
\text { TM with } \\
\text { T.S patch }\end{array}$ & Total \\
\hline Mucosal & $21.2 \%$ & $0 \%$ & $12.1 \%$ & $6.1 \%$ & $9.1 \%$ & $3 \%$ & $51.5 \%$ \\
\hline Squamous & $11.8 \%$ & $17.6 \%$ & $11.8 \%$ & $17.6 \%$ & 0 & $23.5 \%$ & $82.3 \%$
\end{tabular}

Table II : Pre-operative Otoscopic abnormalities in TM of CLE

This study shows that retracted PT was the most common otoscopic finding in TM of the CLE in case of mucosal disease while retracted PF was the least common finding. Similarly, in case of squamosal disease the most common otoscopic finding in the TM were the patients who presented with retracted TM with T.S patch while the least common findings in the TM was thin TM.

\begin{tabular}{|ccccccc|} 
Type of COM & \multicolumn{2}{c}{ Pre-op } & \multicolumn{4}{c|}{ Post-op } \\
\cline { 2 - 7 } & Abnormal & Normal & Total & Abnormal & Normal & Total \\
\hline Mucosal & $51.6 \%$ & $48.4 \%$ & $100 \%$ & $30.30 \%$ & $69.70 \%$ & $100 \%$ \\
\hline Squamous & $82.30 \%$ & $17.70 \%$ & $100 \%$ & $64.70 \%$ & $35.30 \%$ & $100 \%$ \\
\hline
\end{tabular}

Table III : Post-operative otoscopic abnormalities of CLE

Out of 50 cases, the total number of patients with abnormalities of TM (on post-op otoscopic examination) in the CLE were 21 (42\%). In the post-operative assessment out of 33 mucosal disease, 17 cases who had initial abnormality in the CLE had regression of pathologies in 7 cases but 10 patients (30.3\%) continued to have it. There was apparent decrease in aural pathology in 7 cases, making pathologically free CLE's in total 23 cases of mucosal disease (69.7\%).

Of those17 subjects who had squamous type COM, there were 14 (82.3\%) cases having shown some pathology in the CLE's. Among these, the cases with abnormality in CLE reduced from 14 to $11(64.7 \%)$ with increasing normal appearing tympanic membrane from 3 to 6 (35.3\%). (Table III)

\begin{tabular}{|cccccccc|}
$\begin{array}{c}\text { Type of } \\
\text { COM }\end{array}$ & $\begin{array}{c}\text { Retracted } \\
\text { PT }\end{array}$ & $\begin{array}{c}\text { Retracted } \\
\text { PF }\end{array}$ & $\begin{array}{c}\text { T.S } \\
\text { patch }\end{array}$ & $\begin{array}{c}\text { Opaque } \\
\text { TM }\end{array}$ & $\begin{array}{c}\text { Thin } \\
\text { TM }\end{array}$ & $\begin{array}{c}\text { Retracted } \\
\text { TM+T.S } \\
\text { patch }\end{array}$ \\
\hline Mucosal & $6.1 \%$ & $0 \%$ & $12.1 \%$ & $3 \%$ & $6.1 \%$ & $3 \%$ \\
\hline Squamous & $5.8 \%$ & $11.8 \%$ & $11.8 \%$ & $11.8 \%$ & $0 \%$ & $23.5 \%$ \\
\hline
\end{tabular}

Table IV: Post -op otoscopic abnormality of CLE Tympanic membrane

Mucosal type of COM on follow up: Out of 33 cases, 5 cases with size of perforation up to $30 \%$, morphology and hearing were normal on contralateral side and remained so in all but one who initially having had grade II retraction became normal on follow up. Of another 19 cases, 12 cases on contra-lateral side were normal and remained so, 4 cases had tympanosclerosis and 2 atrophic TM that showed no change on follow up. However, one case from each of these above group showed change during follow up, and that was the opaque and thick TM normalizing in morphology in one and in other grade II retraction becoming grade I. The remaining 9 cases having more than $50 \%$ loss of TM showed that grade I retraction of PT became normal on follow up in 3 cases, but one case grade I retraction, another with atrophic PT and yet another with normal drumhead remained unchanged. Furthermore, one case each of grade II retraction and other one with thin TM became normal whereas a case with grade II retraction improved to grade I. Therefore, in 33 cases of mucosal type COM the CLE had pathology in 17 on initial examination that normalized during follow-up in 7 cases but in 10 cases retained the pathology.

Squamous type of COM on follow up Out of 17cases of COM squamous type 9cases did not change morphology of TM in CLE on follow up. Of 17 cases, 3 cases 2 ears each with atrophic membrane and TS patches, one case each of dimpled PF and thickened membrane retained remained initial morphology. Other 5 cases with initial PT retraction bettered their grade of retraction. Furthermore, one case each of PT retraction, atrophic membrane and attic dimple became normal. Overall, 14 cases had abnormal morphology on initial examination of which 11 ears retained that pathology and 3 ears revealed betterment in the status of their pathology on follow up. (Table IV)

Among the 50 patients assessed, the patients with mucosal disease with mild hearing loss was 7 (21\%), none of them had moderate hearing loss while 26 of them (78\%) presented with normal hearing. Similarly, the patients with squamosal disease with mild hearing loss was $5(29 \%)$, moderate hearing loss was $2(11 \%)$ and 10 patients (58\%) presented with normal hearing. Out of 50 cases that was assessed, 14 cases (28\%) had defective hearing while 36 cases $(72 \%)$ had normal hearing in the CLE respectively. (Figure 1)

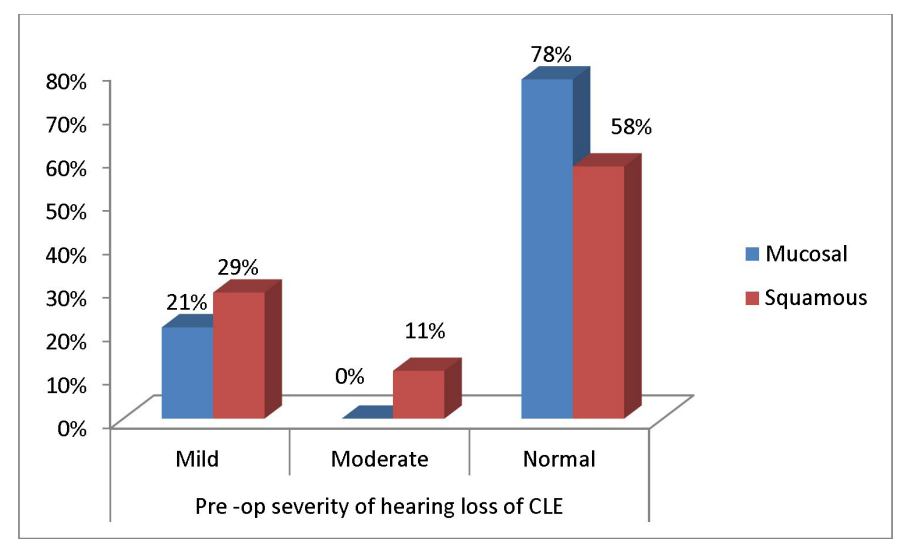

Figure 1: Pre-op Severity of hearing loss

\begin{tabular}{|c|ccc|}
\hline Type of COM & Mild & Moderate & Normal \\
\hline Mucosal & $9 \%$ & $0 \%$ & $90 \%$ \\
\hline Squamous & $29 \%$ & $0 \%$ & $70 \%$ \\
\hline
\end{tabular}

Table V: Post -op severity of hearing loss of CLE

Among the 50 patients assessed, the patients with mucosal disease with mild hearing loss reduced from 7 to 3 (from 21\% to $9 \%$ ), none of them had moderate hearing loss while the number of patient with normal hearing increased from 26 to 
30 (from $52 \%$ to $90 \%$ ). Similarly, the number of patients with squamosal disease with mild hearing loss remained the same i.e. $29 \%$, none of them had moderate hearing loss and the patient with normal hearing increased from 10 to 12 (58\% to $70 \%$ ). Out of total 14 cases of defective hearing in contralateral ears 6 cases had improved hearing and in 8 cases hearing did not improve. (Table V)

\section{DISCUSSION}

Dawood MR (2018) reported the incidence of otoscopic structural abnormalities of CLEs to be mainly TM retraction in case of squamous type and thinning TM in mucosal type of COM. ${ }^{11}$ Furthermore it is interesting to note from this study that in Mucosal type of otitis media the remnants of PT of TM were either atrophic or retracted with sclerosis and chalk patches. Where as in cases of squamous type COM the PT was very often thickened dull and opaque and also had sclerosis and chalk patches. It may or may not perhaps be due to actually OME only. This observation is in agreement with Chauhan B, Chauhan K (2013) who ascertained that the functioning of ET has a direct impact on normal ME function. ${ }^{12}$ Out of 33 cases of COM mucosal, 14 had undergone tympanoplasty. For out of 17 case of squamous COM, 16 had undergone MRM and radical mastoidectomy in single case. In the post-operative assessment of the CLE, of those subjects who had mucosal type COM had regression of pathologies in 7 cases but 10 patients continued to have it. Similarly of those subjects who had squamous type COM with mild hearing loss remained the same i.e. $10 \%$, none of them had moderate hearing loss and the patient with normal hearing increased from 10 to 12 (20\% to $24 \%$ ). In a study done by ShireenAzizkutty, Mubeena., Mohammed N. A. most of the Tympanic membranes were abnormal, with contralateral ear of squamous disease showing more abnormality. Retraction and thinning were the most common abnormalities and $14.3 \%$ cases of pars tensa retractions in squamous cases were grade $4 .{ }^{13}$ In our study $62 \%$ had some sort of pathologies in CLE TM. Nine percentage of TMs were thinned out. Deguine found that the tympanic membrane in the contralateral ears of unilateral cholesteatoma patients was normal in only one third of cases..$^{14}$ In our study cholesteatoma was not seen in any cases.

\section{LIMITATION}

The Small sample size and study design are the major limitation of this study. It could have been analytical and comparative but again due to small size sample statistical significance could not be shown.

\section{CONCLUSION}

The present study has highlighted the possibility of existence of latent pathological process in CLE. We could also show significant regression in pathology of TM and improvement in air conduction; bone conduction in the CLE after treatment of diseased ear. His knowledge can be effectively used in therapeutic planning of diseased ear counselling of patient regarding other ear and if necessary providing therapeutic intervention in other ear at the earliest. The high incidences of occurrence of abnormality in CLE indicate that both ears should be regarded as a pair. The unilateral COM should not be taken as a static phenomenon but as a continuous process in other ear too. We could also show a significant improvement in the CLE after treatment of diseased ear, this knowledge can be effectively used in therapeutic planning of diseased ear, counseling of patient regarding other ear and if necessary providing therapeutic intervention in the other ear at the earliest.

\section{REFERENCES}

1. Ruddy J, Bickerton RC. Optimum management of the discharging ear. Drugs. 1992 Feb 1;43(2):219-35.

2. Adhikari P, Khanal S, Bhatta R, Sigdel S, Baral D. Status of contralateral ear in patients with chronic otitis media. Internet J Health. 2009;20(2):1-6.

3. Browning GG, Merchant SN, Kelly G, Swan IR,Canter R, Mckerow WS. Chronic otitis media. In:The Ear, Hearing and Balance, Scott-Browns Otorhinolaryngology, Head and Neck surgery. 7th edition. Great Britain: Hodder Arnold. 2008:3420-3433.

4. Damghani MA, Barazin A. Alterations in the contralateral ear in chronic otitis media. Iranian journal of otorhinolaryngology. 2013;25(71):99.

5. Selaimen da Costa S, Rosito LP, Dornelles C, Sperling N. The contralateral ear in chronic otitis media: a series of 500 patients. Arch Otolaryngol Head Neck Surg. 2008;134(3):290-3.

6. Giebink GS, Ripley ML, Shea DA, Wright PF, Paparella MM. Clinical histopatological correlations in experimental otitis media: implications for silent otitis media in humans. Pediatr Res 1985; 19(4):389-97.

7. Paparella MM, Hiraide F, Juhn SK, Kaneco J. Cellular events involved in middle ear fluid production. Ann RhinolOtolLaryngol. 1970; 79(4):766-79.

8. Yoon TH, Paparella MM, Schachern PA, Lindgren BR. Morphometric studies of the continuum of otitis media. Ann OtolRhinolLaryngol Suppl. 1990; 148:23-7.

9. Bluestone CD.Epidemiology and pathogenesis of chronic suppurative otitis media: implications for prevention and treatment. Int J PediatrOtorhinolaryngol 1998; 420: 207-223.

10. Jadia S, Mourya A, Jain L, Qureshi S. Pre and Postoperative Status of contralateral ear in unilateral chronic otitis media. Indian Journal of Otolaryngology and Head \& Neck Surgery. 2016; 68(1):20-4.

11. Dawood MR. Otoscopic, radiological, and audiological status of the contralateral ears in patients with unilateral chronic suppurative otitis media. Indian Journal of Otology. 2018;24(1):16 
Bhandari et al.: Assessment of the Status of Contralateral Ear in Post-Operative Subjects of Unilateral Chronic Otorrhoea

12. Chauhan B, Chauhan K. A chronic otitis media comparative study of eustachian tube functions in normal and diseased ears with tympanometry and video nasopharyngoscopy. Indian Journal of Otolaryngology and Head \& Neck Surgery. 2013;65(3):468-76.

13 AddShireen AK Mubeena, Mohammed NA.Status of contralateral ear in unilateral chronic otitis media .IntJOtorhinolaryngol Head Neck Surg2017

14. Deguine C. The contralateral ear in cholesteatoma. Rev LaryngolOtolRhinol (Bord). 1990;11(5):463 